\title{
10. Unruly Bodies of Code in Time
}

\author{
Marisa Leavitt Cohn
}

\begin{abstract}
This chapter examines how debates about the (im)materiality of software comes to inhabit the practices of software engineering work who manage the temporality of obsolescence and its entanglement with their own careers, language proficiencies, and expertise during the lifetimes of systems they develop or maintain. It describes how bodies of code endure materially in ways that exceed their formal understanding, revealing how the hardwiring of temporality into digital systems takes place through a moral economy of software work that devalues of code as it ages and obsolesces. The habitus of the programmer is set within a disciplinary regime that sustains the imaginary of software as immaterial, infinitely flexible and malleable in spite of routine encounters with its material recalcitrance.
\end{abstract}

Keywords: Maintenance, software work, temporality, legacy systems, obsolescence

That which decays is not software.

This is a claim I encountered after giving a presentation of my work to an audience of colleagues at my university that included designers, social scientists, and engineers. I had spoken about the concept of "convivial decay," a term I have used to describe the achievement of engineers working to maintain aging and obsolescing infrastructure. ${ }^{1}$ In the talk I had spoken about the different forms of decay that engineers encounter-from instruments shorting out, to programming languages reaching end of support, to obsolescing standards for software change management. After the talk, one of my colleagues, a software engineer who also provides IT support to some of the university labs, explained to me that while intriguing, I had made an error in claiming that software decays. "Software doesn't decay," 
he said, "everything but the software decays." I understood his contention. "Sure," I replied, "but then, where is this software? Where does this thing that does not decay exist?" He laughed at my question, dismissing it as a philosophical concern best left for an afterwork conversation.

This disagreement reflects a debate between materialist and immaterialist views on the nature of software that has animated much discussion among scholars of computational media. We have, for example, the assertion from Kittler in his well-known essay "There is no software," that "all code operations, despite their metaphoric faculties ... come down to absolutely local string manipulations and that is, I am afraid, to signifiers of voltage differences." ${ }^{2}$ On the other hand, we have claims that what is most essential to the nature of software is its "operativity"3 or "executability," an abstraction that exists outside of the particular instantiations of hardware and software that "coalesce" in order for the code to function. ${ }^{4}$

Rather than stake out a position within this debate, my aim in this chapter is to ask how this debate comes to inhabit the discourses and practices of software engineering work. In my ethnographic fieldwork, programmers and software engineers inevitably deal with material instantiations of code, particularly in cases where they are working with long-lived systems running on legacy software. Aging software systems require engineering methods that are similarly forensic and archaeological as the methods of media scholars unpacking historical or residual media. Yet at the same time, these encounters with the materiality of code, while commonplace, still seem to rupture with regularity a strongly held belief in software as immaterial, as that which does not decay.

Materialist approaches to software are often adamantly reliant upon engineering know-how. Kittler wishes to give engineering knowledge primacy as the proving ground for theorization. ${ }^{5}$ Others in software studies have debated whether you can theorize software without being a proficient coder. And, as Dourish points out, when technologists work with code, the material constraints of software systems are unavoidable. "Programmers understand the ways in which digital structures can resist their will, every bit as much as clay, wood, or stone. ...Materiality - the nature of the substrates and the properties that constrain and condition the designerly encounter-is at the core of each experience." ${ }^{\prime 6}$ If engineers know this materiality of software so well, why does an immaterial view have such staying power? Why and how is an immaterial view of software privileged and sustained despite the obviousness of its materiality?

What I suggest here is there is an overlooked temporal dimension to this tension between software as material/immaterial. As software ages, its 
materiality becomes more and more unruly, more recalcitrant. A new line of code just written by a solitary coder/theorist might be easy to change, but once embedded into the complexity of interoperating systems being maintained by multiple generations of engineers, such changes become the object of much organizational scrutiny and negotiation. Bodies of code are increasingly bound up in the contingencies of historical organizational decisions, material constraints of available technologies, as well as the careers of those maintaining the code.

Through empirical material drawn from ethnographic fieldwork with a large engineering organization, I argue that what is at stake in this tension are the valuations of different forms of computational work over others. The negotiations that take place in managing aging software are not only a matter of securing computational systems from disastrous changes; they are also a matter of how engineers manage the temporality of obsolescence and the entanglement of their own careers, language proficiencies, and expertise with the lifetimes of systems they develop or maintain.

If we were to track the biography of a software system over time, we might observe an unfolding process of its materialization that mirrors in many ways a process of decommodification described by Kopytoff.7 As software ages it becomes increasingly "singular, unique, and unexchangeable" and embedded into the social milieu of the organization. Those who want to commoditize their expertise must then detach themselves from the concerns of particular bodies of code and their accidental materialities, and align with more universal, timeless ideals of code as immaterial. It is through this marginalization of material concerns, I argue, that an immaterial view of software is sustained within the moral economy of software work.

The following vignettes are taken from ethnographic fieldwork conducted in 2010-2011 with the Cassini mission to Saturn at the Jet Propulsions Laboratories. The case offers an extreme example of engineers working with a long-lived infrastructure built to maintain and command a spacecraft navigating in orbit around Saturn, that was built and launched in the 1990s. While the hardware and software on-board the spacecraft is over a decade old, so too is much of the software used to command it (known as the "ground system") because it must remain compatible with the spacecraft. Nonetheless, there are plenty of pressures towards upgrade and adaptation on the mission, due to programming languages reaching end of support, new software management methodologies in vogue at the lab, as well as down-sizing of personnel requiring the "leaning" of software work.

These vignettes are snapshots from within the lifetime of the mission that capture the entangled biographies of engineering careers and bodies of 
code. $^{8}$ As Kopytoff notes, a cultural analysis of the biographies we tell about objects can reveal a "moral economy that stands behind the objective." $\mathrm{We}$ can hear in these vignettes, evaluations of what constitutes a successful career or a good software system. What is negotiated in the stories told to me about the mission and its software systems are the attachments, both economic and affective, that are formed with software over time. In the discussion that follows the vignettes, I unpack further how time and code are figured together within these stories, and how particular affective attachments to code are pathologized and devalued.

\section{Vignette 1: "Gripping the Casket"}

William is a navigator who has joined the Cassini mission quite recently but who loves the work, which he says is the most exciting work of navigation going on at the Lab. No other mission has as much navigation work to be done on an ongoing basis, and he associates much prestige with the fact that mission still knows the location and trajectory of its spacecraft with such precision and is still flying successfully after so many years. But William also sees that many of the ways of doing navigation work at the mission have become entrenched and is eager to get on board with new software developments at the Lab-to harness the "power" of new software.

When I arrived and for full duration of my time in the field, the navigation team was struggling to migrate to a new software system, and so were running in what they called "parallel ops"-flying the spacecraft with two software systems at the same time. These software tools are used to determine and analyze the spacecraft's current vector in space (i.e. where it is and where it is currently headed) and to plan upcoming maneuvers (for example "trimming" an orbit by firing thrusters). ${ }^{10}$ Cassini was a new "customer" to a multi-mission software system called MONTE that had long replaced the legacy system on all other missions at the lab. Cassini was the only mission coming on board to the tool after launch and during the long-term maintenance and operations phase of the work, after the team has built up over a decade of experience with the spacecraft's behavior and the tools used to navigate it.

William explained that for many of the old-timers, navigators who had worked on the Cassini mission since its launch, they could not see the value of the new system. For one thing, he explained, there is the question of why you would try to learn a new programming language when you are "ten years deep" in another. He also discussed the risk of doing too much 
work to adopt and adapt a new software tool. Working on software is "not our job description" and does not have much visibility within the organization. But despite this William had decided to develop an interface with the new software, through the creation of a new design mark-up language (an Interface Description Language, IDL), that would accommodate the mission's need to run multiple analyses in parallel by adopting the same naming conventions used to keep the various potential solutions distinct. Over multiple meetings he tried pitch the new language to his own team and to lab-wide meetings of navigators with the hopes that this would allow his team to interface with the new software while maintaining older ways of working.

William was particularly sensitive to the fact that navigation work can change dramatically in nature depending on the software tools one uses. He views working on software as a way of showing deep care for the mission and the work that they do, but also a risk to one's career. Aligning to software work can make one indispensable if you are the only person who knows that tool, which could be bad in the long run if some other more exciting mission comes up. It also puts you at risk of becoming a software person and being seen as someone to ask to write code rather than to design a mission tour.

"If anything it can be harmful for you. They hired me because I know astronautics, they don't care about my coding. I could become the code guy and be downgraded to writing scripts for others. Instead of oh William is a $\mathrm{PhD}$ rocket scientist, so have him design the maneuver, [it could be] oh no, William is good for coding, put him there. So sometimes it is to your own detriment to write good code."

Yet for William, working with the new software was also a matter of distancing himself from the legacy systems in operation at Cassini that are no longer relevant. At a meeting with other navigators at the lab demonstrated his new interface design language in a presentation on the unique challenges faced by the Cassini mission which he outlined as a set of ten "pathologies" within the legacy navigation database led to wasted effort. ${ }^{11}$ Through this presentation, William works to demonstrate to his fellow navigators at the lab that even within the context of a mission that is perceived as a "dinosaur" he is capable of staying innovative and up to date in his ways of thinking about navigation work. By positioning himself against the legacy software to his broader professional network at the lab, William made sure that while he was aligned to the mission system, he was not aligned to the software code in the same way that his colleagues were.

His failures to get his team on board with the new design language aside, his ability to narrate his own practice in the terms of the current 
technoscientific paradigm by pathologizing the legacy software aligned him to new disciplinary regimes, to such an extent that he was even called out for "selling out" by one of his colleagues. Yet from his perspective, William sees some of his colleagues as making the wrong kinds of alignments to the legacy software, saying that they are "fearing the corpse but gripping the casket."

\section{Vignette 2: Surfacing a bug}

Another navigator, Chris, explained to me that he came to the Cassini mission fresh out of his masters degree and found himself caught off guard by the reality of his engineering work - being "thrown into the deep end of [programming in] Unix." Having had no introduction to it in school required him to make a "big leap" to work in a space with so little of the programming skills he needs everyday. He confessed to me that due to this lack of experience with he "seem[s] to attract software bugs ... or weird problems." He attributed this to the idiosyncrasies of his work, that he might have configured something ever so slightly wrong or done something a slightly different way. And then "all of a sudden," he tells me, "I get a bug." "[And all the] old-timers are in my office staring at me wondering how could you do that?!" He gives me an example of how one time, he was running a small test on a file through a program in his own file space when suddenly he modified an actual operations file that he should not have access to. "Technically I wasn't even supposed to have permission to edit [it]. And yet here I am doing my own little work ... And well people were starting to panic, wondering ... why is this input looking like this? how is he able to do it? Is the system not secure? I ran a little thing on the side and suddenly I'm corrupting our operations ... and it ended up being ... just a weird flaw in the legacy file."

Chris seems simultaneously a bit abashed but also in awe of the fact that by virtue of being new and knowing less and doing something "wrong" or at least off the normal path he actually lead to a kind of discovery of an anomaly hidden in the depths of the software system, something no one knew was there. "I'm like trying to follow everything [they're saying]. I actually learned a lot that way. And so did everybody else." He laughs and explains that engineers much more experienced than him "the old timers" were standing around his terminal saying "I didn't know you could do this or I didn't know you could do that." "And I just did it," he adds.

In fact, everything about the way Chris explained this story came across as a kind of confession, as if he were speaking in a way that he shouldn't. His 
voice lowered to a whisper and his tone implied both an apology for how things work on such an old mission, and an appreciation for a system that has been around for so long. He laughed uneasily as he told me this story and added that when he hears about the legacy code "I hear people say 'the legacy code has been around for more than 40 years'" he thinks about how it accrued over time as a kind of "patchwork" one that spans many people's careers, many hands having touched it over the years. And while he agreed that the new ways of developing code, these newer programming languages and platforms, do make code more maintainable, more evolvable, flexible and extensible, at the same time this software being developed today, "I wouldn't say, I can't say that this software will last another 40 years. Who knows how long it is going to be relevant ..." When I ask if after he surfaced this bug in the system, were they able to fix it. "Not really, but [we could] just be more aware of [it]. We call those 'features.' When it is something that you can't change and is just the way it is. It's a feature. Like we have features," he says, as he gestures to his face.

\section{Vignette 3: Return Tour of Duty}

Reza is a software developer who began working at the lab in 1995 and soon after began working on the Cassini mission in 1996 when they were nearing their launch date. Like Chris, Reza took an apologetic tone when explaining to me what he finds inspiring about working on this project. Over the duration of his career, he had moved around a lot from mission to mission, and it was only recently that he had been brought back in to work on the Cassini mission. He had been tasked with jumping in to get a piece of code working again that had broken when the person who wrote it had left. I had asked him about what he was working on. Like Chris he could not believe I would be interested in work he was doing with legacy code. But, he explained, that is work he enjoys doing, picking up some code written by other people. "Half of my career has been doing that actually, that is just part of software development. You always enter a project. You're seldom aligned [so that] you're there right at the beginning... . Or," he continues, laughing, "there's always, even if you are right there right at the beginning, some projects inherit code from other projects."

I asked Reza what he likes about working with legacy code and he points to a few things. First, he likes what he calls the "detective work." "It is a matter of going through the code and trying to decipher what was the intention, what was he trying to [do]? What was the product he was trying to create 
[and] why didn't it get created. Because [there's] the trail. You can see what he was trying to do." He also liked that working with old software held nostalgia for him. Returning to a mission where he worked years back as a young engineer, he encounters some of the same systems that were written at those times. He described coming back to Cassini as a return tour of duty, and it was in a tone of duty and care that he spoke about the mission as one that provides a good working environment precisely because of the care that has been put into it over so many years by so many engineers. And it was also the "diversity" of a project where you might work one day in something like a really "old X/Motif GUI that is not refreshing properly ... and from there I go to something like Drupal which I knew nothing about yet... It's just constantly changing." In contrast, he said that working on some of the newer missions made him feel like a programmer that is just a replaceable cog in the system. He said the work is "cookie-cutter"-the work broken down in a Fordist like manner making his work repetitive and his own prior experience irrelevant.

\section{Discussion}

In these vignettes, we see how software work involves affective attachments, as well as detachments, from ways of working with code. In William's story, he admonishes his colleagues for forming attachments to particular ways of working with obsolescent software systems in ways that might be detrimental to their careers. On the other hand, he is called out for being too careless in how he cuts ties from old ways of working with software, and too self-interested in how he capitalizes on a narration of the mission's software systems as backwards and pathological. Meanwhile, in Chris and Reza's accounts of the Cassini software, there is also an apology for the forms of attachments one makes to legacy software. For Chris, as a young engineer, he knows he is not supposed to find novelty and intrigue in a system that is so old - a "well-oiled machine." Like William, he hints at a more proper and expected allegiance to the newer systems and ways of working. He explains that the new systems are indeed better, parroting the terms "extensible, maintainable, evolvable" in a voice that signals ideological-speak.

Chris's experience working with legacy systems has disrupted a particular ideological attachment that he has encountered in the broader discipline of software engineering, one that overvalues current systems and their anticipated futurity. What does it mean, after all, for a system to be more 
maintainable than one that has been maintained for over 40 years? Systems are durable, not because of some attribute of the programming paradigm in which they arise, but simply by virtue of people contributing to keep it going. Taking this even further, Reza's appreciation for legacy code (one that he consistently apologized for) suggests that what is gained with newer systems is not so much a cure-all against obsolescence, but a way to ensure that histories are continuously truncated. If the new software is more "maintainable" it is in the sense that has become increasingly commoditized. But in order for code to act as a commodity it must also be effaced of the historicity that gives Reza pleasure in working with legacy code.

These stories reveal competing valuations of software, as well as of ways of knowing and becoming affectively attached to software. One can care too much for code in ways that are detrimental to career or one can be too careerist in cutting ties from old code. A paradox presents itself in the idea that one can be overly attached to the material concerns of software, yet it is clear that such attachments are what keeps a system going, since the code remaining operative relies on people who maintain proficiency and understanding with legacy languages. It is also clear that while there are competing valuations, there is one that dominates, inflecting the awe and richness that both Chris and Reza see in the legacy code with apology and irony. This speaks to the power of the disciplinary regime that governs proper attitudes of the coding subject.

In thinking through these affective ties to old code and how they were disavowed by Chris and Reza, I was reminded not only of Foucault's discussion of governmentality but also his essay on Technologies of the Self (Foucault 1988) in which he asks "through what operations we work upon our bodies and souls, thoughts, and conduct ... so as to transform themselves in order to attain a certain state of ... purity, wisdom, perfection, or immortality." While Foucault is talking about the techniques applied to the body, we can easily extrapolate to techniques applied to the body of code, as I have done so here by adapting his questions for my purpose:

- If one wants code to behave rationally and if we want to regulate code according to certain principles of what makes code rational, what part of code or ones work of coding should one renounce?

- How do individuals effect by their own means or with others a set of operations on the body of code, on their conduct towards the code, so as to transform the code into a state of perfection?

These questions apply quite readily to the context of software development as seen in the vignettes above. They help to highlight two modes of knowing 
and attaching to code. The mode of innovation in which one does not align too closely to any aging or obsolescent system. And the mode of maintenance and care in which one understands code materially through its longevity and an attachment to the past as a source of insight. In the first code is commodified, current, and promises longevity through a renunciation of obsolescence. In the latter, the code itself is a rich tapestry or patchwork that binds together many different careers that sustain the body of code's longevity - that is a way of knowing code that is rooted in continuity rather than in a regime of anticipation and futurity. ${ }^{12}$

Others have pointed out that software is bound up with philosophical commitments and morality. ${ }^{13}$ What I have highlighted here is how the moral economy of software work also applies to its aging and obsolescence. As John Durham Peters states, "obsolescence always raises moral questions about the subjects and objects we neglect"14. In the aging and obsolescence of software, time and code are configured together. In long-lived systems, particular temporalities of work must be maintained in order for the system to remain vital, and likewise a system can "fail" for lack of those who know how to program in older languages. At the same time, valuations of software also shift as it ages. Old software resists commodification, displays too much personality, bugs becoming features. In software engineering communities, legacy is considered a derogatory word, referring to code that has stuck around too long and become heavy. Old software is pathologized for being mired in the past, and those who care too much for it are as well. Even the terms used in software engineering to manage aging systems like rot and grime ${ }^{15}$ suggests a relation to the abject. At the same time, newer systems and methods are adopted with a rhetorical promise of eternal youth, as the solution that will never age.

A materialist approach to software contends that the "trope of immateriality" is both analytically weak, smoothing over technical complexity, and ideological in suggesting that digital systems liberate us from the historical and material contingencies of other media. ${ }^{16}$ Drawing on Hayles, Blanchette suggests that this trope is part of an ideological project that has as its underlying "fundamental assumption, that informational patterns (including human consciousness) are ontologically superior to their (accidental) material instantiations (including the human body). ${ }^{\prime 17}$ This same ideology inhabits software programming work, in part because it is a feature of obsolescence that an engineer can liberate himself from the contingencies of the at-times arbitrary material conditions of the past by choosing to write new code rather than maintain the old. It is thus also the habitus of the programmer set within these disciplinary regimes that 
forms part of the mundane apparatus sustaining the imaginary of software as immaterial, infinitely flexible and malleable.

\section{Conclusion}

Ernst has claimed that "temporal transcendence of materiality is a faculty of operative media" in the sense that there is such a "tight coupling" between elements of hardware and the material knowledge of them, that they act as a kind of time machine. When technologies are reactivated at a later time they might require modification to get them working, but this is done in such a way that "unleashes" the "latent presence" of their operations. ${ }^{18}$ What he points to is the way that the "operation" itself endures in ways that the material instantiations do not. This makes sense for understanding the transience of software's material instantiations and how older systems become a repository of memory of older ways of working (as they did, for example for Reza). However, this fails to make sense of how bodies of code endure materially in ways that exceed their formal understanding.

As software ages, it can become no longer executable because of some perturbation in the many interdependencies of a body of code and the people who operate it. A person moves off the project, or a subsystem fails, and the organizational memory is no longer there, if it ever was, to hold the system together. This suggests that legacy software might become unable to temporally transcend its materiality simply because the tight coupling of hardware and knowledge has been lost. But it also, I think, betrays a presentist bias in how we philosophize the nature of software that leaves aside the problem of temporalities of software's aging and obsolescence. That is, even when we examine the historicity of computational media, our analysis privileges how this historicity is made manifest in the present. What about the latency of a bug in 50-year old software, as an aspect of its (in)operativity, that is only revealed over the long lifetime of software. The bug, which might also become a feature, is a constitutive part of software as both a material and formal object.

As I have hoped to show, the hardwiring of temporality in digital systems, is at least in part performed through the valuations of software as it ages. Such valuations arise not only with regard to the performativity or executability of code, but also in regard to the multiple biographies of any body of code, the many lives and careers it has touched or sustained. In a culture where as code ages and becomes more mired in material concerns, the work of maintaining it is devalued and even pathologized, privileges accrue to 
the software yet to be written. This ethos shapes the attachments and moral commitments of engineers to competing valuations of maintenance and innovation. As in rubbish theory, legacy code is that which is not yet thrown away but is durable despite its devaluation and troubles the moral economy of software work. ${ }^{19}$ It is in this duration of unruly bodies of code in time that the ideology of "immateriality" lives.

\section{Notes}

I would like to thank Axel Volmar and Kyle Stine for organizing the series of workshops on Hardwired Temporalities as well as the participants in those workshops for their feedback on this piece, particularly Gabriele Schabacher, Geoffrey Bowker, and Alexander Monea for their in-depth comments. I also appreciate input from Nanna Thylstrup and Mace Ojala who significantly advanced my thinking in later drafts.

1. See Marisa Leavitt Cohn, "Convivial Decay: Entangled Lifetimes in a Geriatric Infrastructure," in Proceedings of the 19th ACM Conference on Computer-Supported Cooperative Work and Social Computing (ACM, 2016), 1511-1523.

2. $\quad$ Friedrich Kittler, "There Is No Software," Stanford Literature Review 9, no. 1 (Spring 1992): 84 .

3. Wolfgang Ernst, "Micro-Dramaturgical Temporalities of Media Theatre: On the Difference Between Performative and Operative Reenactment," in Performing Arts in Transition: Moving between Media (New York: Routledge, 2019), 55-68.

4. Rob Kitchin and Martin Dodge, Code/Space: Software and Everyday Life (Cambridge, MA: MIT Press, 2011).

5. $\quad$ Friedrich Kittler, "Real Time Analysis, Time Axis Manipulation," Public Culture 13, no. 1 (2017): 1-18.

6. Paul Dourish, The Stuff of Bits: An Essay on the Materialities of Information (Cambridge, MA: MIT Press, 2017), 6.

7. Igor Kopytoff, "The Cultural Biography of Things: Commoditization as Process," The Social Life of Things: Commodities in Cultural Perspective 68 (1986): 64-91.

8. Steven J. Jackson, David Ribes, Ayse Buyuktur and Geoffrey C. Bowker, "Collaborative Rhythm: Temporal Dissonance and Alignment in Collaborative Scientific Work," in Proceedings of the ACM 2011 Conference on Computer Supported Cooperative Work (ACM 2011), 245-254.

9. Kopytoff, "Cultural Biography of Things," 64.

10. There are many reasons that the navigation team found it difficult to switch to the new software system. In contrast to the legacy code, which was developed "in house" at the Cassini mission, adapted from earlier missions to suit Cassini's needs, the new software system was developed by a new multi-mission software team at the lab that maintains a code base 
and unit tests to keep the software working for multiple missions at once. While other missions can provide requirements for the system and work in advance of launch to test out the software, Cassini was the only mission expected to change to the new software mid-flight. Not only was the new software producing different results from the legacy software (literally plotting different vectors for the spacecraft's current trajectory), but each time the new software was successfully tweaked to produce results for Cassini's navigation team, some new update to the software would break the team's in-house tools. Many of the initial issues discovered in transitioning to the new software came down to the material instantiation of the code. For example, the new software was written in Python, which stores variables differently than the legacy code, in terms of how it handles truncation of decimals. These types of fixes were relatively easy to deduce, but never fully brought the tools into perfect congruence. The new software also ran very slowly, something that is less of an issue for missions that design one set of navigation maneuvers and parameters for a successful launch and entry into a planet or stable orbit. The Saturn mission, however, had to consider multiple maneuvers to execute on a weekly basis.

11. Many of these so-called pathologies came from inheritances from even earlier missions that had done most of their navigation calculations by hand. The legacy software draws on what was originally a digitized version of paper files, which unlike a modern database did not have a clear separation between form, syntax, and content. What used to be considered a "view" of the database (a print out) is what is now treated as data.

12. Adrian Mackenzie, "Programming Subjects in the Regime of Anticipation: Software Studies and Subjectivity," Subjectivity 6, no. 4 (2013): 391-405.

13. Paul Dourish, Where the Action Is: The Foundations of Embodied Interaction (Cambridge, MA: MIT Press, 2004); Christopher Kelty, “Geeks, Social Imaginaries, and Recursive Publics," Cultural Anthropology 20, no. 2 (2005): 185-214; E. Gabriella Coleman, Coding Freedom: The Ethics and Aesthetics of Hacking (Princeton, NJ: Princeton University Press, 2012).

14. John Durham Peters, "Proliferation and Obsolescence of the Historical Record in the Digital Era," in Cultures of Obsolescence. History, Materiality, and the Digital Age, ed. Babette B. Tischleder and Sarah Wasserman (New York: Palgrave Macmillan, 2015), 79-96.

15. Clemente Izurieta and James M. Bieman, "A Multiple Case Study of Design Pattern Decay, Grime, and Rot in Evolving Software Systems," Software Quality Journal 21, no. 2 (2013): 289-323.

16. Jean-Francois Blanchette, "A Material History of Bits," Journal of the American Society for Information Science and Technology 62, no. 6 (2011): 10421057, https://doi.org/10.1002/asi.21542.

17. Blanchette, "Material History of Bits," 1044.

18. Ernst, "Micro-Dramaturgical Temporalities of Media Theatre."

19. See Michael Thompson, "Time's Square: Deriving Cultural Theory from Rubbish Theory," Innovation 16, no. 4 (2003): 319-330. 


\section{About the Author}

Marisa Leavitt Cohn is an Associate Professor in the Technologies in Practice group at the IT University of Copenhagen where she co-directs the ETHOS Lab. She combines anthropological and design-oriented approaches to the study of human computer interaction focusing on temporalities of work in long-lived infrastructures and legacy system maintenance. 